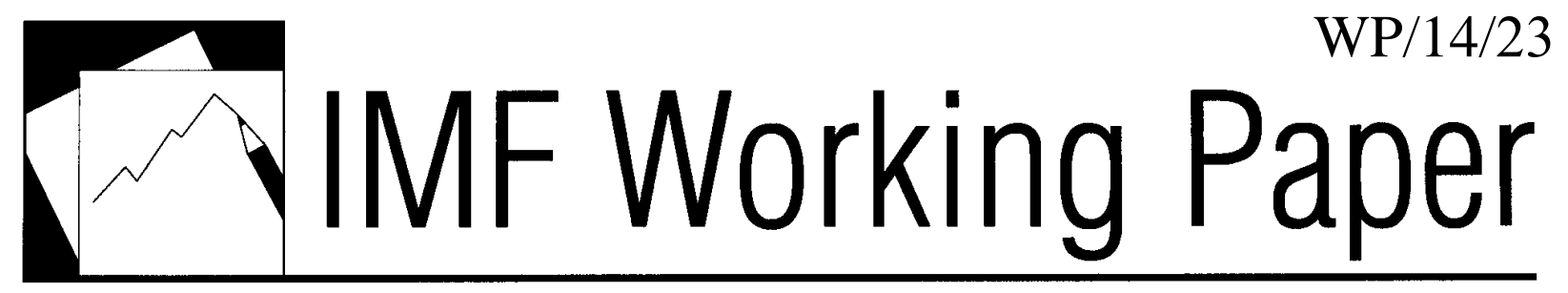

\title{
Aggregate Stability and Balanced-Budget Rules
}

Matteo F. Ghilardi and Raffaele Rossi 


\title{
IMF Working Paper
}

\author{
Research Department
}

Aggregate Stability and Balanced-Budget Rules

Prepared by Matteo F. Ghilardi and Raffaele Rossi*

Authorized for distribution by Andrew Berg and Catherine Pattillo

February 2014

\begin{abstract}
This Working Paper should not be reported as representing the views of the IMF.

The views expressed in this Working Paper are those of the author(s) and do not necessarily represent those of the IMF or IMF policy. Working Papers describe research in progress by the author(s) and are published to elicit comments and to further debate.
\end{abstract}

It has been shown that under perfect competition and a Cobb-Douglas production function, a basic real business cycle model may exhibit indeterminacy and sunspot fluctuations when income tax rates are determined by a balanced-budget rule. This paper introduces in an otherwise standard real business cycle model a more general and data coherent class of production functions, namely a constant elasticity of substitution production function. We show that the degree of substitutability between production factors is a key ingredient to understand the (de)stabilising properties of a balanced-budget rule. Then we calibrate the model consistently with the empirical evidence, i.e. we set the elasticity of substitution between labour and capital below unity. We show that compared to the Cobb-Douglas case, the likelihood of indeterminacy under a balanced-budget rule is greatly reduced in the United States, the European Union and the United Kingdom.

JEL Classification Numbers: E32; E62.

Keywords: Constant Elasticity of Substitution; Fiscal Policy; Indeterminacy; Business Cycles.

Author's E-Mail Address: mghilardi@imf.org,r.rossi@lancaster.ac.uk

\footnotetext{
* We would like to thank Pok-sang Lam and two anonymous referees for their insightful comments. Furthermore, we are grateful to Fabio Canova, Cristiano Cantore, Paul Levine, Peter McAdam, Malcolm McColl, Giovanni Melina, Giorgio Motta, Patrizio Tirelli, Aleh Tsyvinski and the participants at seminars at University of Milano-Bicocca and University of Surrey for helpful comments. The views expressed herein are those of the authors and should not be attributed to the IMF, its Executive Board, or its management.
} 


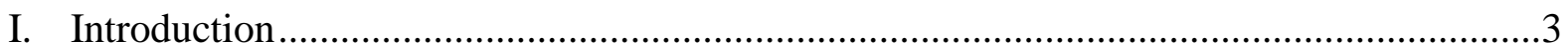

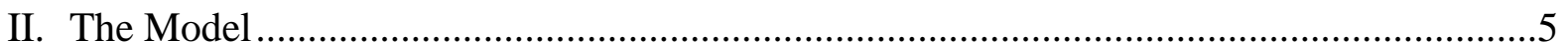

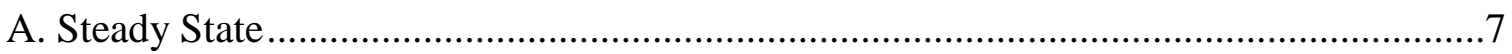

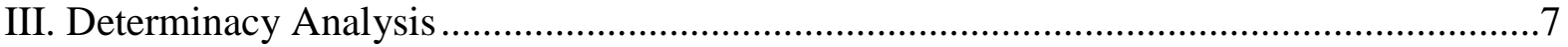

A. Intuitions: a Closer Look at the Labour Market and the Laffer Curve ........................10

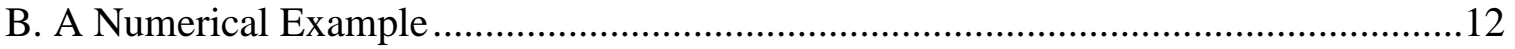

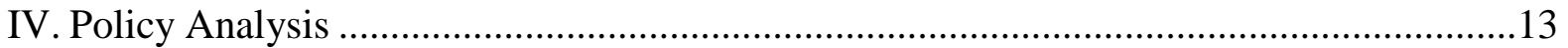

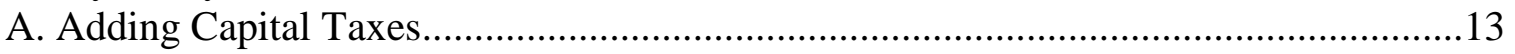

B. An Empirical Perspective on the Elasticity of Substitution ......................................14

C. Balanced-Budget Rules and Determinacy Analysis in the US, EU and UK................16

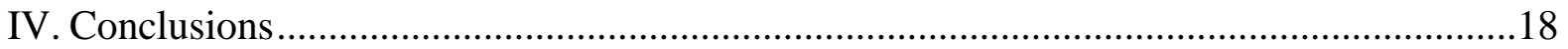

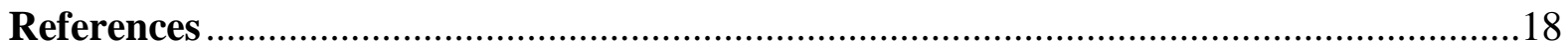

\section{Appendix}

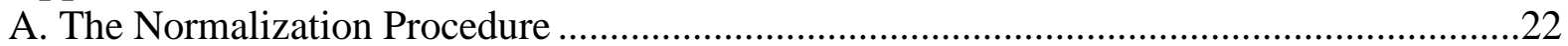

B. The Log-Linearized System ...............................................................................22

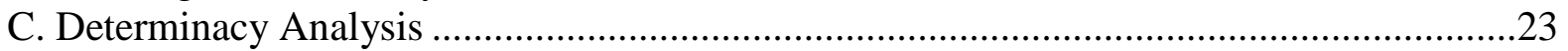

\section{Tables}

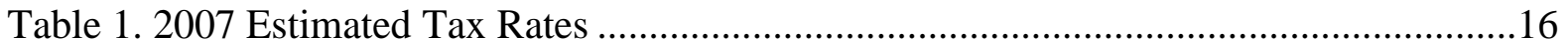

Table 2. Threshold values of $\sigma$ necessary for determinacy in 2007 ....................................17

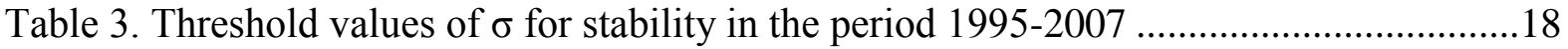

\section{Figures}

Figure 1. Determinacy Analysis with Labour Tax Only ................................................12

Figure 2. Determinacy Analysis with Labour and Capital Taxes .........................................13

Figure 3. Endogenous Capital and Labour income Rate for the Empirical Range of $\sigma$..........17 


\section{Introduction}

A recurring debate in American politics regards the possibility of inserting in the US constitution the requirements that federal government operates under a balanced budget rule (BBR). Indeed, most states have constitutional or statutory limitations restricting their ability to run deficits in the state's general fund. Balanced-budget limitations may be either prospective (beginning-ofthe-year) requirements or retrospective (end-of-the-year) requirements. The European Union, after the sovereign debt crisis in Greece and Italy, is introducing the so called 'Fiscal Compact'. This pact requires that the government budgets shall be balanced or in surplus, with a maximum level of annual structural deficit of $0.5 \%$ of GDP.

In the economic literature there is no shortage of discussion on the BBR. Both traditional business cycle literature (see among others Lucas and Stokey, 1983, King et al., 1988, Eggertsson 2008) and political economy literature (see among others Alesina and Perotti 1996; Besley and Smart 2007; Azzimonti et al. 2010) study under different perspectives the normative properties of adopting a BBR. A different strand of literature focuses on the stabilising properties of a BBR on equilibrium determinacy. The main contribution to this can be found in Schmitt-Grohè and Uribe (1997). The authors find that in a standard neoclassical growth model with indivisible labour isomorphic to Hansen (1985) or King et al. (1988), imposing on the fiscal authority a balanced-budget requirement may induce self-fulfilling expectations, hence indeterminacy. The intuition behind this result goes as follows: under a BBR, when agents expect higher tax rates in the future, for a given level of capital stock, hours worked and therefore the rental rate of capital will be lower (the marginal product of capital is decreasing in the capital/labour ratio). The decrease in expected return on capital lowers current labour supply via its effect on the marginal utility of income, leading to a decline in current production. Given that the tax base is an increasing function of income, the government is obliged, following a BBR to increase the tax rate today. This countercyclical tax policy will help fulfill agents' initial expectations, thus leading to indeterminacy of equilibria and endogenous business cycle fluctuations. Furthermore, as Schmitt-Grohè and Uribe show, a BBR would generate indeterminacy in the group of G7 countries if they were to adopt it.

This paper extends Schmitt-Grohè and Uribe's model by considering a more general class of production functions, namely the constant elasticity of substitution (CES) production functions as in Arrow et al. (1961), which nest the traditional Cobb-Douglas (CD) as a particular case. We justify the introduction of this production technology into an otherwise basic real business cycle workhorse model in two ways. Firstly, from a purely theoretical point of view, by simply varying a single model's parameter, namely the elasticity of substitution between production factors, the CES can be used to treat the production inputs, i.e. labour and capital, both as gross complements (elasticity of substitution below one) or gross substitutes (elasticity of substitution above one). Secondly, from an empirical point of view, recent studies, i.e. Antràs (2004), Klump et al. (2007, 2012), León-Ledesma et al. (2010a), reject the CD specification in 
favour of CES production function in which labour and capital are gross complements.

We obtain two sets of results. First, we show analytically that the degree of substitutability between production factors is a key ingredient to understand the (de)stabilising properties of a BBR. Second, when we parametrise the model consistently with the empirical evidence, i.e. elasticity of substitution below unity, the instability problems that affect the Schmitt-Grohè and Uribe model are greatly reduced. Nevertheless, for parameter values at the high end of these estimates, sunspot equilibria are still possible for the US, the EU and the UK.

The main intuition behind this result goes as follows. When the elasticity of substitution between capital and labour is below unity, production factors are gross complements. This causes labour hours to be more tightly coupled to the stock of capital. Consequently, equilibrium hours worked can respond less freely to belief shocks, reducing the possibility of generating the type of endogenous fluctuations which characterise the CD case.

The results presented in this paper link to the existing literature in several ways. Firstly, our paper is closely related to Guo and Lansing (2009). Guo and Lansing also use a normalised CES production function and analyse numerically the effect of the elasticity of substitution between capital and labor for indeterminacy. In their model, a discrete-time version of a modified Benhabib and Farmer's (1994) indeterminate one-sector RBC model under laissez-faire, the possibility of indeterminacy derives from increasing returns to scale due to a production externality. In the present paper, it derives from the fiscal increasing returns property of a proportional income tax that is used to balance the government's budget each period, such that a larger economy coincides with a lower tax rate. Both papers find that decreasing the elasticity of substitution decreases the possibility of indeterminacy. With respect to Guo and Lansing, the originality of our theoretical contribution stands in explicitly deriving the analytical conditions of how the elasticity of substitution affects the indeterminacy of the model and to apply these conditions to a well defined fiscal policy problem.

Secondly, it links to the literature on the stabilising properties of a BBR. Giannitsarou (2007), using a discrete time version of Schmitt-Grohè and Uribe (1997) model, focuses on the stabilising role of consumption taxation. Using the same framework, Linnemann (2008) argues that the stability properties of a BBR may improve sensibly when a class of non-separable utility functions are considered. In a similar fashion, Stockman (2010) derives theoretical conditions to obtain chaotic equilibria under a BBR.

From this, the goal of the paper is twofold. First, it derives the analytical conditions of how the elasticity of substitution affects the stability of a widely used theoretical model. Second, it aims to develop an interest in the use of CES production technology in the analysis of economic policy issues. 
The rest of the paper is organised as follows. Section 2 presents the model with only labour tax and the determinacy analysis. Section 3 adds capital taxation to the benchmark model and discusses the policy implications of introducing a BBR in the US, EU and UK. Section 4 concludes.

\section{The Model}

In this section we derive analytically the main results of the paper. In order to do this we analyse a continuous-time one sector real business model which consists of households, firms and government. Government purchases are constant and the only source of government revenues is a labour income tax. The initial stock of public debt is zero and the government is subject to a balanced-budget requirement. The government budget constraint is given by $G=\tau_{t}^{h} H_{t} w_{t}$, where $G$ indicates government purchases of goods, $\tau_{t}^{h}$ denotes labour tax rate, $w_{t}$ the pretax wage, and $H_{t}$ hours worked. Firms hire labour and rent capital in a perfectly competitive manner. We generalise the standard CD production function by employing a normalised version of the CES production function. This represents the only difference between the model presented here and the one in Schmitt-Grohè and Uribe (1997).

The economy is populated by a unit measure of identical infinitely-lived households. Each household starts in period 0 with a positive stock of capital, $K_{0}$ and chooses path for consumption, $C_{t}$, hours and capital, so to maximise the present value of its lifetime utility. The disutility of labour is linear. In mathematical terms, each household solves:

$$
\max \int_{0}^{\infty} e^{-\rho t}\left(\log C_{t}-A H_{t}\right) d t
$$

subject to $K_{t} \geq 0$ and to the standard budget constraint:

$$
\dot{K}_{t}=\left(\mu_{t}-\delta\right) K_{t}+\left(1-\tau_{t}^{h}\right) w_{t} H_{t}-C_{t}
$$

where $\rho \in(0,1)$ is the subjective discount factor, $A \in[0,+\infty)$ is a standard utility parameter, $\mu_{t}$ denotes the rental rate of capital, $\delta \in(0,1)$ is the depreciation rate. A dot above a variable denotes the time derivative, so $\dot{K}_{t}$ is net investment. The first order conditions associated with this problem are:

$$
\begin{gathered}
A C_{t}=\left(1-\tau_{t}^{h}\right) w_{t} \\
\dot{C}_{t}=\left(\mu_{t}-\delta-\rho\right) C_{t}
\end{gathered}
$$

The first equation states that the slope of the indifference curve of the representative household equates to the slope of the after tax real wage. The second equation is the consumption 
Euler equation. Alongside those we have the following transversality condition:

$$
\lim _{t \rightarrow \infty} e^{-\rho t} \frac{K_{t}}{C_{t}}=0
$$

The representative firm produces output $Y_{t}$, hires labour at a rate $w_{t}$ and rents capital at a rate $\mu_{t}$ according to a CES production function of the type:

$$
Y_{t}=B\left[\alpha\left(K_{t}\right)^{\frac{\sigma-1}{\sigma}}+(1-\alpha)\left(H_{t}\right)^{\frac{\sigma-1}{\sigma}}\right]^{\frac{\sigma}{\sigma-1}}
$$

where $\alpha \in(0,1)$. Note that when $\sigma=1$ the CES collapses to the CD case, when $\sigma \rightarrow 0$ it collapses to the Leontief case where capital and labour are perfect complements, while when $\sigma \rightarrow \infty$, capital and labour become perfect substitutes.

Let $F_{H}$ and $F_{K}$ denote the first derivatives of the production function with respect to labour and capital respectively. The representative firm maximises the stream of profit:

$$
\max \int_{0}^{\infty} e^{-\rho t}\left(Y_{t}-w_{t} H_{t}-\mu_{t} K_{t}\right) d t
$$

subject to the production function as defined in eq. (6). The first order conditions for this problem are:

$$
F_{H, t}=w_{t}=(1-\alpha) B\left(\frac{Y_{t}}{H_{t}}\right)^{\frac{1}{\sigma}}
$$

and

$$
F_{K, t}=\mu_{t}=\alpha B\left(\frac{Y_{t}}{K_{t}}\right)^{\frac{1}{\sigma}}
$$

These two equations state that the marginal products of the production inputs equate to their corresponding prices. Following Klump and de LaGrandville (2000), Guo and Lansing (2009) and Cantore et al. (2013), we "normalise" the standard CES production function so that all steady-state allocations and factor income shares are held constant as the input substitution elasticity is changed. Normalisation removes the problem that arises from the fact that labour and capital are measured in different units, see Klump and Marianne 2008. Under CD, normalisation plays no role since, due to its multiplicative form, differences in units are absorbed by the scaling constant. The CES function, by contrast, is highly non-linear, and so, unless correctly normalised, out of its two key parameters - the distribution parameter $\alpha$ and the substitution elasticity $\sigma$ - only the latter is deep. The former turns out to be affected by the size of the substitution elasticity and factor income shares. Accordingly if one is interested in model sensitivity with respect to production parameters (as here), normalisation is essential to have interpretable comparisons. Given the aim of the paper we normalise the CES with a CD production function. ${ }^{1}$

\footnotetext{
${ }^{1}$ We refer the reader to the Appendix for an outline of the normalisation procedure.
} 
In order to complete the description of the model we need to define the aggregate resource constraint for the economy as:

$$
Y_{t}=C_{t}+G+\dot{K}_{t}+\delta K_{t}
$$

\section{A. Steady State}

The adopted normalisation implies that our model shares the same steady state as SchmittGrohè and Uribe (1997). Given the distortive nature of fiscal policy, in the steady state there is a Laffer curve-type of relation between tax rates and tax revenues. From the steady state relations of the endogenous variables, it is easy to show that government revenues are zero when tax rates are either zero or one and positive in between. Provided that government revenues are a continuous function of the tax rate, there must be a $\tau^{h *}$ that maximises $G$. In turn $\tau^{h *}$ can be found as the solution of $\frac{\partial G}{\partial \tau^{h}}=0$ as:

$$
G \frac{(1-\bar{\alpha})\left(\tau^{h}\right)^{2}-2\left(1-\bar{\alpha} \frac{\delta}{\delta+\rho}\right) \tau^{h}+\left(1-\bar{\alpha} \frac{\delta}{\delta+\rho}\right)}{\tau^{h}\left(1-\tau^{h}\right)\left(1-\tau^{h}(1-\bar{\alpha})-\bar{\alpha} \frac{\delta}{\delta+\rho}\right)}=0
$$

where $\bar{\alpha}$ is the income share of capital (i.e. the usual CD parameter) obtained via the normalisation procedure and $\frac{\delta}{\delta+\rho}$ is independent of $\tau^{h}$. Note that for $\tau^{h} \in(0,1), G$ and the denominator are always positive. ${ }^{2}$ So $\tau^{h *}$ corresponds with the zeros of the polynomial:

$$
(1-\bar{\alpha})\left(\tau^{h}\right)^{2}-2\left(1-\bar{\alpha} \frac{\delta}{\delta+\rho}\right) \tau^{h}+\left(1-\bar{\alpha} \frac{\delta}{\delta+\rho}\right)
$$

When $\tau^{h}=0$ the above expression takes the value of $1-\bar{\alpha} \frac{\delta}{\delta+\rho}>0$, while when $\tau^{h}=1$ it takes the value of $\bar{\alpha}\left(\frac{\delta}{\delta+\rho}-1\right)<0$. Hence one of the zeros happens when $\tau^{h} \in(0,1)$ and the other when $\tau^{h}>1$. Therefore there is a unique maximum of government revenues, $\tau^{h *}$ between 0 and 1.

\section{Determinacy Analysis}

We log-linearise the structural equations around a normalised steady state. As previously discussed, we follow the normalisation procedure presented by Guo and Lansing (2009) and Cantore et al. (2013). This allows us to use the CD production function as a steady state

\footnotetext{
${ }^{2}$ To see why the denominator is positive, note that $1-\tau^{h}(1-\bar{\alpha})-\bar{\alpha} \frac{\delta}{\delta+\rho}>1-(1-\bar{\alpha})-\alpha \frac{\delta}{\delta+\rho}$. The latter can be written as $\bar{\alpha}\left(1-\frac{\delta}{\delta+\rho}\right)$ which is positive.
} 
benchmark. After some straightforward manipulations we can rewrite the model as one involving just two dynamic variables, namely consumption and capital accumulation (see Appendix $\mathrm{B}$ for details of the log-linearisation). The model can be represented as:

$$
\left[\begin{array}{c}
\dot{c}_{t} \\
\dot{k}_{t}
\end{array}\right]=\left[\begin{array}{cc}
-(\delta+\rho)\left(\frac{(1-\bar{\alpha})\left(1-\tau^{h}\right)}{\bar{\alpha}-\sigma \tau^{h}}\right) & -(\delta+\rho) \frac{1}{\sigma}\left(1+\bar{\alpha} \frac{1-\sigma \tau^{h}}{\sigma \tau^{h}-\bar{\alpha}}\right) \\
\frac{Y}{K} \sigma(1-\bar{\alpha}) \frac{\tau^{h}-1}{\bar{\alpha}-\sigma \tau^{h}}-\frac{C}{K} & \frac{Y}{K} \bar{\alpha}\left(\frac{-\sigma \tau^{h}+1}{\bar{\alpha}-\sigma \tau^{h}}\right)-\delta
\end{array}\right]\left[\begin{array}{c}
c_{t} \\
k_{t}
\end{array}\right]
$$

where a lower case variable identifies its log-linearised value and a variable without time index identifies its steady state value. Let $J$ be the matrix of this linear system. Since (12) contains one predetermined, $k_{t}$, and one non-predetermined variable, $c_{t}$, the perfect-foresight equilibrium will be locally determinate if, and only if, the two eigenvalues of $J$ have different signs. Since the determinant of $J$ is the product of its eigenvalues, the system is determinate if and only if the determinant of $J$ is negative. However, if the determinant is positive and the trace (which is the sum of the eigenvalues of $J$ ) is negative, i.e. both eigenvalues of $J$ are negative, the perfect-foresight equilibrium will be indeterminate. Finally, if both the determinant and the trace of $J$ are positive, i.e. both eigenvalues of $J$ are positive, the perfect-foresight equilibrium will be unstable. The determinant and trace of $J$ are respectively:

$$
\begin{gathered}
\operatorname{Det}(J)=\frac{\delta(\rho+\delta)(1-\bar{\alpha})}{\frac{\delta \alpha}{\delta+\rho}(\sigma \tau-\bar{\alpha})}\left((1-\bar{\alpha})\left(\tau^{h}\right)^{2}-2\left(1-\bar{\alpha} \frac{\delta}{\delta+\rho}\right) \tau^{h}+\left(1-\bar{\alpha} \frac{\delta}{\delta+\rho}\right)\right) \\
\operatorname{Trace}(J)=\frac{(\rho+\delta)\left(1-\sigma \tau^{h}\right)-(\rho+\delta)\left(\left(1-\tau^{h}\right)(1-\bar{\alpha})\right)}{\bar{\alpha}-\sigma \tau^{h}}-\delta
\end{gathered}
$$

The next two propositions describe the possible equilibrium outcomes.

Proposition 1 Necessary and sufficient conditions for equilibrium determinacy are:

$$
\begin{aligned}
\text { if } \sigma & \in[\bar{\alpha},+\infty) \Longrightarrow \tau^{h} \in\left[0, \min \left(\frac{\bar{\alpha}}{\sigma}, \tau^{h *}\right)\right) \text { or } \tau^{h} \in\left(\max \left(\frac{\bar{\alpha}}{\sigma}, \tau^{h *}\right), 1\right] \\
\text { else } \sigma & \in[0, \bar{\alpha}) \Longrightarrow \tau^{h} \in\left[0, \tau^{h *}\right)
\end{aligned}
$$

Proof. See Appendix C. 
Proposition 2 Define $\varepsilon=\frac{\bar{\alpha} \rho}{\rho \sigma-(1-\bar{\alpha})(\delta+\rho)}$. The following four cases fully categorise all the model outcomes:

a) If $\sigma \in\left[0,1+\frac{\delta(1-\bar{\alpha})}{\rho}\right]$ and $\frac{\bar{\alpha}}{\sigma}<\tau^{h *}$, the model is indeterminate if $\tau^{h} \in\left(\frac{\bar{\alpha}}{\sigma}, \tau^{h *}\right)$ and determinate if $\tau^{h} \notin\left(\frac{\bar{\alpha}}{\sigma}, \tau^{h *}\right)$.

b) If $\sigma \in\left[0,1+\frac{\delta(1-\bar{\alpha})}{\rho}\right]$ and $\frac{\bar{\alpha}}{\sigma}>\tau^{h *}$, the model is unstable if $\tau^{h} \in\left(\tau^{h *}, \min \left(\frac{\bar{\alpha}}{\sigma}, 1\right)\right)$ and determinate if $\tau^{h} \notin\left(\tau^{h *}, \min \left(\frac{\bar{\alpha}}{\sigma}, 1\right)\right)$.

c) If $\sigma \in\left(1+\frac{\delta(1-\bar{\alpha})}{\rho},+\infty\right)$ and $\varepsilon>\tau^{h *}$, the model is indeterminate if $\tau^{h} \in\left(\frac{\bar{\alpha}}{\sigma}, \tau^{h *}\right)$ and determinate if $\tau^{h} \notin\left(\frac{\bar{\alpha}}{\sigma}, \tau^{h *}\right)$.

d) If $\sigma \in\left(1+\frac{\delta(1-\bar{\alpha})}{\rho},+\infty\right)$ and $\varepsilon<\tau^{h *}$, the model is indeterminate if $\tau^{h} \in\left(\frac{\bar{\alpha}}{\sigma}, \varepsilon\right)$ and unstable if $\tau^{h} \in\left(\varepsilon, \tau^{h *}\right)$ and determinate if $\tau^{h} \notin\left(\frac{\bar{\alpha}}{\sigma}, \tau^{h *}\right)$.

\section{Proof. See Appendix C.}

Proposition 1 and 2 state the main result of the paper. Under a BBR, the elasticity of substitution between production factors changes markedly the determinacy properties of the model. A few points are noteworthy here. First, $\tau^{h *}$ is not a function of $\sigma$. This is a direct consequence of the normalisation procedure, i.e. at steady state the Laffer curve is independent of $\sigma$. Second, the threshold tax rate which may cause model's instability is not only a function, as in Schmitt-Grohè and Uribe (1997), of the steady state share of capital to output $\bar{\alpha}$, but also and in a non-trivial way of the elasticity of substitution between input factors $\sigma$. When the complementarity between factors increases, i.e. when $\sigma$ is smaller, the possibility of determinacy when the model is on the upper slope of the Laffer curve increases, while the opposite is true when $\sigma$ gets bigger. ${ }^{3}$ Furthermore, it is interesting to note that for particularly low values of $\sigma$, i.e. when $\frac{\bar{\alpha}}{\sigma}>\tau^{h *}$, the model is determinate for any $\tau^{h}<\tau^{h *}$.

Proposition 2 classifies the equilibrium outcomes when the model displays some sort of sunspot fluctuations, i.e. either stationary or not. Unlike the CD specification we are able to induce instability in the system when the labour income tax is the only source of government revenue.

\footnotetext{
${ }^{3}$ Note that our results perfectly nest Schmitt-Grohè and Uribe (1997) when $\sigma=1$.
} 


\section{A. Intuitions: a Closer Look at the Labour Market and the Laffer Curve}

The equilibrium conditions obtained can be explained by the interactions between the shape of the Laffer curve and the effect of $\sigma$ on the "equilibrium labour demand schedule" (LDS henceforth). As in the Schmitt-Grohè and Uribe model, our LDS may slope upwards since increases in aggregate hours worked are accompanied by decreases in the tax rate. As we describe in detail later, this is the central mechanism that generates indeterminacy in the model. ${ }^{4}$ In our framework, the elasticity of substitution between factors greatly modifies the LDS slope, in turn affecting markedly the equilibrium outcomes. To see why, let us write the after-tax labour demand function (in log deviation from steady state) as:

$$
\widetilde{w}_{t}=\frac{\tau^{h}-\bar{\alpha} / \sigma}{1-\tau^{h}} h_{t}+\frac{\bar{\alpha} / \sigma}{1-\tau^{h}} k_{t}
$$

where $\widetilde{w}_{t} \equiv \hat{w}_{t}-\frac{\tau^{h}}{1-\tau^{h}} \hat{\tau}_{t}^{h}$ denotes the log deviation of the after-tax wage rate from the steady state. Note that if $\tau^{h}<\frac{\bar{\alpha}}{\sigma}$ the slope of the LDS is negative while it is positive in the opposite case, i.e. if $\tau^{h}>\frac{\bar{\alpha}}{\sigma}$. It is worth stressing that the elasticity of substitution parameter implies that the higher the complementarity (substitutability) between production factors, the higher (lower) is the steady state tax rate threshold that flips the sign of the LDS slope.

According to Proposition 1 and Proposition 2, indeterminacy occurs when jointly the LDS slopes upwards and $\tau^{h}<\tau^{h *}$, i.e. we stand on the increasing side of the Laffer curve. The intuition behind this goes as follows: let us assume the economy is on the increasing side of the Laffer curve and the LDS slopes upwards. In this scenario, when agents expect higher tax rates in the future, for a given level of capital stock, hours worked and therefore the rental rate of capital will be lower. This is because the marginal product of capital is decreasing in the capital/labour ratio. In turn, since consumers want to invest less in the future, there is a decrease in current aggregate employment and a decline in output. Given that we are on the increasing side of the Laffer curve, the government is obliged, following a BBR, to increase taxes today. Hence, expectations of higher taxes in the future lead to higher taxes today thus generating self-fulfilling prophecies.

As $\sigma$ decreases below unity, production factors become gross complements. This causes the demand of labour to be more tightly coupled to the stock of capital, which is predetermined. Consequently, hours worked can respond less freely to belief shocks. In other words, when $\sigma$ is 'low', the LDS is likely to slope downward, inducing current aggregate employment to increase when agents expect higher taxes. This leads to lower taxes today thus making endogenous fluctuations more difficult to occur. In the case where $\sigma \leq \bar{\alpha}$, the economy will be determinate

\footnotetext{
${ }^{4}$ The same mechanism generates indeterminacy in the one-sector growth model with increasing return analysed in Benhabib and Farmer (1994).
} 
anywhere on the upward sloping part of the Laffer curve. These effects are reversed when production factors are gross substitutes, i.e. $\sigma>1$.

Furthermore, when the model is not determinate and $\tau^{h}<\tau^{h *}$, i.e. the system is on the increasing side of the Latter curve and the LDS slopes upward, sunspot fluctuations are stationary. This is because an increase in current taxation generates a further decrease in the equilibrium hours worked. This decrease pushes fiscal policy to implement a further increase in current taxation. As a result, for a given expected increase in the future tax rate, the tax rate in period 0 is larger in absolute value than the tax rate in period $t^{\prime}$ for any $t^{\prime}>0$. Hence, the sequence of tax rates converges to the steady state, i.e. indeterminacy.

When the steady state tax rate is greater than $\tau^{h *}$, i.e. on the decreasing side of the Laffer curve, a positive slope in the LDS is a necessary condition for determinacy. This is because while expectations of higher future tax rates generate a decrease in current aggregate employment, fiscal policy needs to cut taxes in order raise revenues and therefore to balance its budget, in turn contrasting the initial expectations of higher taxes.

We are also able to induce instability in the model with only labour income tax. This occurs whenever LDS slopes downwards and we stand on the decreasing side of the Laffer curve. The intuition behind this result is the following. Let us consider the case where complementarity between factors is so strong that $\frac{\bar{\alpha}}{\sigma}>\tau^{h *}$, and agents expect higher future taxes. A negative LDS slope implies that equilibrium hours worked increase. Since the system is now on the decreasing side of the Laffer curve, the government needs to raise taxation (to decrease government revenues) in order to balance its budget. While higher taxation today helps to self-fulfill agents' expectations, it decreases current labour demand putting a slight downward pressure on taxes. As a result, (for a given expected increase in the future tax rate) tax rates in period 0 increase less in absolute value than tax rates in period $t^{\prime}$ for any $t^{\prime}>0$. Hence, the sequence of tax rates has an explosive path, i.e. instability.

Finally, note that we can induce instability even when production factors are gross substitute and the tax rate is smaller than the peak of the Laffer curve. This is possibly due to the perverse effect of the high degree of substitutability and the positive LDS slope. However, given that, as discussed below, this occurs for empirically implausible ${ }^{5}$ values of $\sigma$, this result goes beyond the aim of the present exercise. Hence we leave future research to explore this conjecture in more detail.

\footnotetext{
${ }^{5}$ With a standard parametrisation $1+\frac{\delta(1-\bar{\alpha})}{\rho}=2.75$. This value is outside plausible estimates of $\sigma$.
} 


\section{B. A Numerical Example}

In order to show how the elasticity of substitution changes quantitatively the determinacy analysis, we present a numerical example. The model is calibrated to annual frequency. The parameter values, with the obvious exception of $\sigma$, are the same as in Schmitt-Grohé and Uribe (1997) and are $\rho=0.04$ for the annual interest rate, $\delta=0.1$ for the capital depreciation rate, the utility parameter $A$ is calibrated to 1 and the CD capital income share in output is $\bar{\alpha}=0.3$.

In order to have a comprehensive picture of how the elasticity parameter modifies the (de)stabilising properties of a BBR, we allow $\sigma$ to vary between 0.2 and 1.8. These values are extreme from an empirical point of view but useful to give a graphical representation of the theoretical results. ${ }^{6}$
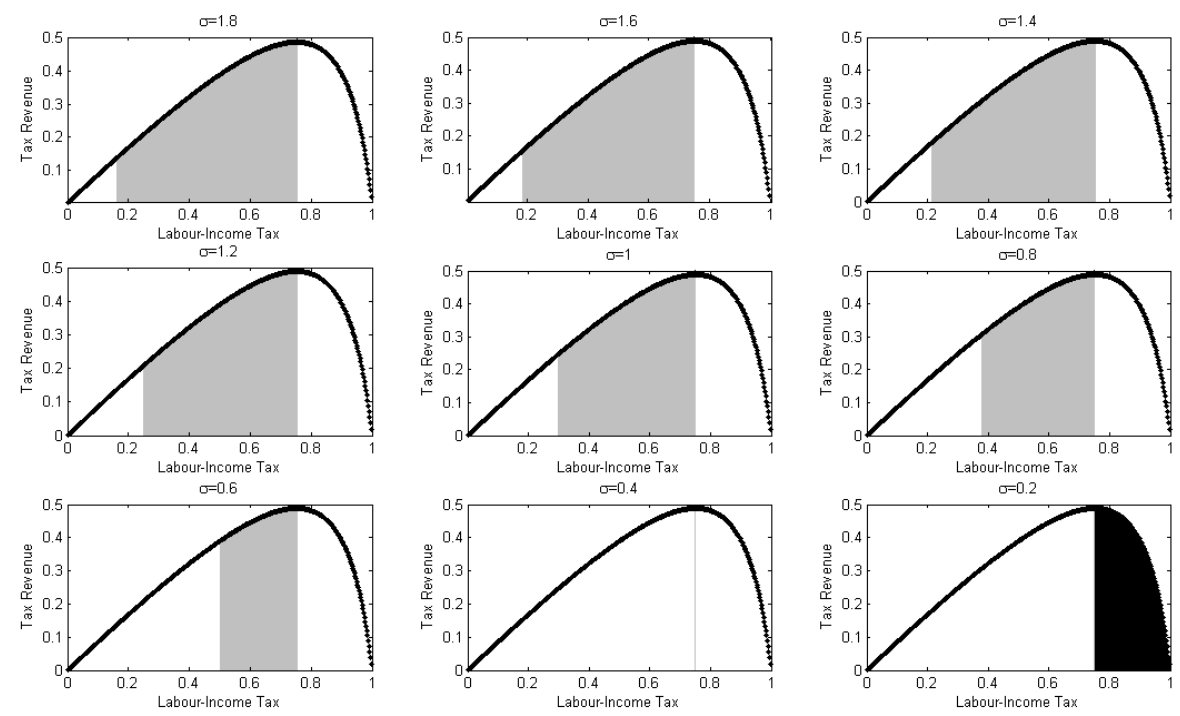

Figure 1 - Determinacy analysis with labour tax only. White area, determinacy. Grey area, indeterminacy. Black area, instability.

Results of this exercise are presented in Figure (1). Each subplot presents the values of labour tax rates that induce determinacy (white area), indeterminacy (grey area) and instability (black area). As discussed in detail before, reducing the value of $\sigma$ reduces the indeterminacy area, in turn expanding the possibility that for a given tax rate, a BBR delivers determinacy. Finally, when $\bar{\alpha} / \sigma>\tau^{h *}$, a BBR may induce instability for steady state labour tax rates greater than the peak of the Laffer curve (bottom right subplot).

\footnotetext{
${ }^{6}$ We refer the reader to section 3 for a detailed discussion on the empirical estimates of $\sigma$.
} 


\section{Policy Analysis}

In this section we examine the empirical relevance of combining a CES production function with a BBR. After introducing capital taxes, we discuss how we define a range of reasonable values for the elasticity of substitution parameter for the US, the EU and the UK and, finally, we show that the likelihood of being in a indeterminate area is sensibly reduced.

\section{A. Adding Capital Taxes}

In this section we extend the basic result to a case where capital income taxation is an additional source of government revenue. ${ }^{7}$ In this case, government budget constraint takes the form:

$$
G=\tau_{t}^{h} w_{t} H_{t}+\left(\mu_{t}-\delta\right) \tau_{t}^{k} K_{t}
$$

where $\tau_{t}^{k}$ is the tax rate and the term $-\tau_{t}^{k} \delta K_{t}$ represents the depreciation allowance. In this analysis we consider the case where government purchases are fixed and $\tau^{h}$ and $\tau^{k}$ vary in the same proportion to balance the budget, i.e. $\hat{\tau}_{t}^{h}=\hat{\tau}_{t}^{k}{ }^{8}$
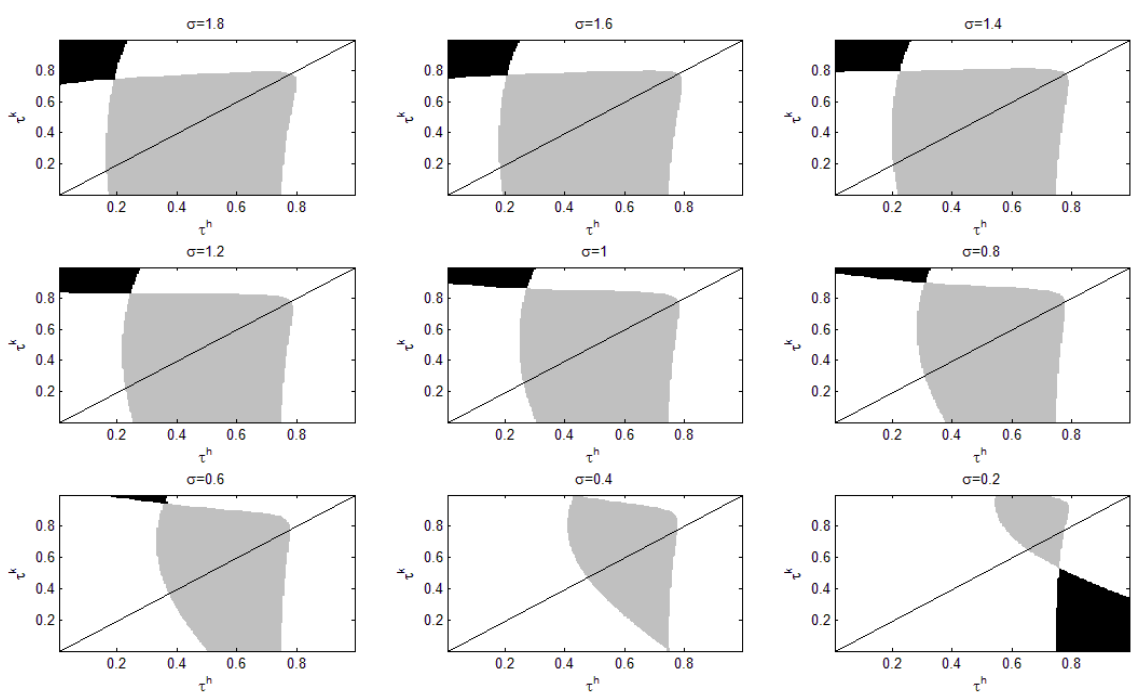

Figure 2 - Determinacy analysis with labour and capital taxes. White area, determinacy. Grey area, indeterminacy. Black area, instability. The pairs $\left(\tau^{h}, \tau^{k}\right)$ for which $\tau^{h}=\tau^{k}$ (the solid line) correspond to the case of an income tax regime with depreciation allowance.

\footnotetext{
${ }^{7}$ Given the aim of the paper we ignore consumption taxes which are a significant source of revenues in the European countries. See Giannitsrou (2007) for a detailed discussion on this theme.

${ }^{8}$ The assumption that capital and labor tax rates vary in the same proportion to balance the

budget may be considered ad hoc and rather arbitrary. We present this in order to make our results easily comparable with Schmitt-Grohè and Uribe (1997) and Giannistorou (2007).
} 
The determinacy analysis is represented in Figure 2. To be consistent with the labour income tax case, we let the elasticity of substitution parameter $\sigma$ vary between 0.2 and 1.8. The solid line represents the points where $\tau^{h}=\tau^{k}$ and it corresponds to the case of an income tax regime with depreciation allowance. As before, each subplot presents the values of labour and capital tax rates that induce determinacy (white area), indeterminacy (grey area) and instability (black area). The central graph represents the CD case discussed by Schmitt-Grohè and Uribe (1997), i.e. $\sigma=1$. Note that if $\tau^{k}=0$, the model collapses to the one analysed in the previous section. As in Schmitt-Grohè and Uribe (1997), Guo and Harrison (2004) and Giannitsarou (2007), the presence of an endogenous labour tax rate is the key destabilising ingredient of the model. If labour taxes are endogenous, as the steady state capital tax rate increases, the range of indeterminacy with respect to labour taxes becomes larger.

However, as described in detail above, decreasing (increasing) the elasticity of substitution between factors decreases (increases) the potential destabilising effects of endogenous labour tax rate, in turn reducing (augmenting) the possibility of indeterminacy for a given mix of capital-labour taxation. ${ }^{9}$

\section{B. An empirical perspective on the elasticity of substitution}

As we discuss above, $\sigma$ is a key parameter to understand the determinacy properties of the model. Therefore, in order to conduct a realistic policy analysis, it is crucial to calibrate the elasticity of substitution between production factors consistently with the empirical evidence. In what follows we provide a brief literature review of the efforts made and the difficulties found in estimating this key parameter. Based on this survey, we conclude with a typical range of values for the elasticity of substitution between labour and capital for the US, the EU and the UK. Then, we use these values in the calibration exercise.

Despite the huge efforts devoted to its estimation, limited consensus has emerged on the value of the substitution elasticity. This doubtless reflects many practical data problems (e.g., outliers, uncertain autocorrelation, structural breaks, quality improvements, measurement errors, etc.) as well as a priori modeling choices and the performance of various estimators. For example, depending on the methodology employed, the existing literature finds values that are both well below and near the unity. Early studies based on cross sectional analysis generally find an elasticity of substitution close to one, i.e. they could not reject a CD production function, see, inter alia, Fuchs (1963), Zarembka (1970) and Dhrymes and Zarembka (1970). Differently, estimates based on time series typically find an elasticity of substitution significantly lower than

\footnotetext{
${ }^{9}$ Note that for extremely strong factor complementarity, i.e. $\sigma=0.2$, the system may display instability for combinations of 'high' level of labour income taxation and 'low' capital income taxation. However, given the empirical implausability of this scenario, we do not explore this result further.
} 
one, implying gross complementarity between production factors, e.g. Lucas (1969) provides a value of $\sigma$ in the range 0.3 to 0.5 , Coen (1969) finds that the best fit occurs when $\sigma=0.2$ and Maddala (1965) estimates values for $\sigma$ between 0.1 and 0.2 . Furthermore, estimates of $\sigma$ based on the marginal productivity of capital tend to be lower than those based on the marginal productivity of labour, i.e. Dhrymes and Zarembka (1970).

In an influential contribution, Berndt (1976) attempts to reconcile these views. He constructs a high quality time series data for the U.S. for the period 1929-1968 and estimates $\sigma$ via a time series two-stages least squares procedure. Using a variety of functional forms and assuming Hicks-neutral technological change, Berndt finds an elasticity of substitution close to one. Antràs (2004) extends Berndt's analysis by allowing for a more general specification of the aggregate technological progress. Firstly, he suggests that the Berndt assumption of Hicks-neutral technical progress, coupled with relatively stable factor shares and growing capital-labor ratio, biases the results towards a CD. ${ }^{10}$ In other words, the assumption of Hicks-neutral technology necessarily biases the estimates of $\sigma$ towards one. Secondly, by allowing for biased technology progress, i.e. technology change is allowed to affect the ratio of marginal products of labour and capital, Antràs finds estimates of $\sigma$ significantly lower than one. He identifies as a typical range for the US of $\sigma$ to be between 0.6 and 0.9 and also acknowledges the possibility for the elasticity of substitution to be lower than 0.5 .

A recent growing literature builds on the time series approach proposed by Antràs that allows for biased technological progress and applies to the CES production function a normalisation procedure isomorphic to the one presented in Section 2. Leon-Ledesma, et al. (2010a) stress the empirical benefits of estimating and identifying normalised production functions, i.e. it simplifies the setting of initial conditions, it provides a neat link between theoretical and empirical production functions and allows ex-post validation of estimated parameters. ${ }^{11}$ Klump, et al. (2007), using a normalised CES function with factor-augmenting technical progress, estimate a three-equation, supply-side system and find elasticity values for the US economy between 0.5 and 0.7. In a similar fashion, Leon-Ledesma, et al $(2010 b, 2011)$ and McAdam and William (2013b) find values of $\sigma$ in the same range.

Given the high variability of the estimated values of $\sigma$, in order to present our results in a robust manner we adopt as parametrisation for the U.S. the interval $(0.5,0.9)$, adopting as a central value $\sigma=0.7$. This parametrisation encompasses most of the recent empirical evidence.

The number of empirical studies on the elasticity of substitution for the UK and the EU is not as large as the for the US. Therefore the parametrisation for these two areas relies on a handful of papers. For the UK, Bolt and van Els (2000), by using a time series two steps

\footnotetext{
${ }^{10}$ Both growing capital/labor ration and constant factor shares are well documented stylised facts of the U.S. post WWII data.

${ }^{11}$ We refer the reader to section 2 for a discussion of the theoretical importance of normalisation.
} 
estimation technique, find a value of $\sigma$ around 0.6. Barnes, et al. (2008) estimate the elasticity of substitution with a panel of UK firms and find an elasticity of substitution between 0.4 and 0.65. As for the Euro Area, Klump, et al. (2007, 2012) estimate a normalised CES production function and find values between 0.6 and 0.7. Bolt and van Els (2000) find a lot of heterogeneity among European countries with values of $\sigma$ that range from 0.24 (Austria) to 0.78 (Belgium). McAdam and William (2013a) report values of $\sigma$ in the interval $(0.65,0.8)$. We therefore conclude that a reasonable range for the UK and the EU for $\sigma$ to be $(0.4,0.8)$ with a central value of 0.6 .

\section{Balanced-budget rules and determinacy analysis in the US, EU and UK.}

This section discusses the policy implications of evaluating a BBR when factors are gross complements. With the exception of $\sigma$ and the tax rates, our results are based on the same parametrisation used for Figures 1 and 2 so that the model is, ceteris paribus, in line with the analysis of Schmitt-Grohé and Uribe (1997). For the tax rates we use the estimation procedure of Mendoza, et al. (1994) for the US, the EU and the UK. Furthermore we parametrise $\sigma$ according to the typical ranges as described above.

We perform two exercises. In the first one, we study the stability properties of the model for the US, the EU and the UK by using the estimated labour and capital tax rates for 2007. In the second exercise we extend this analysis to the period $1995-2007$.

The estimated labour and capital tax rates for 2007 are summarized in Table 1.

Table 1 - 2007 Estimated Tax Rates

\begin{tabular}{ccc}
\hline \hline & Capital Tax & Labour Tax \\
\hline US & 0.382 & 0.284 \\
EU & 0.383 & 0.343 \\
UK & 0.451 & 0.304 \\
\hline \hline
\end{tabular}

The results of the first exercise are presented in Figure 3. This figure presents three subplots, each for different values of the elasticity of substitution. The three parametrisations of $\sigma$ represent the central value as well as the two extremes of the typical range of estimates as presented in the previous section. As discussed above, we assume that both labour and capital taxes are endogeneous and vary in the same proportion along the business cycle. 

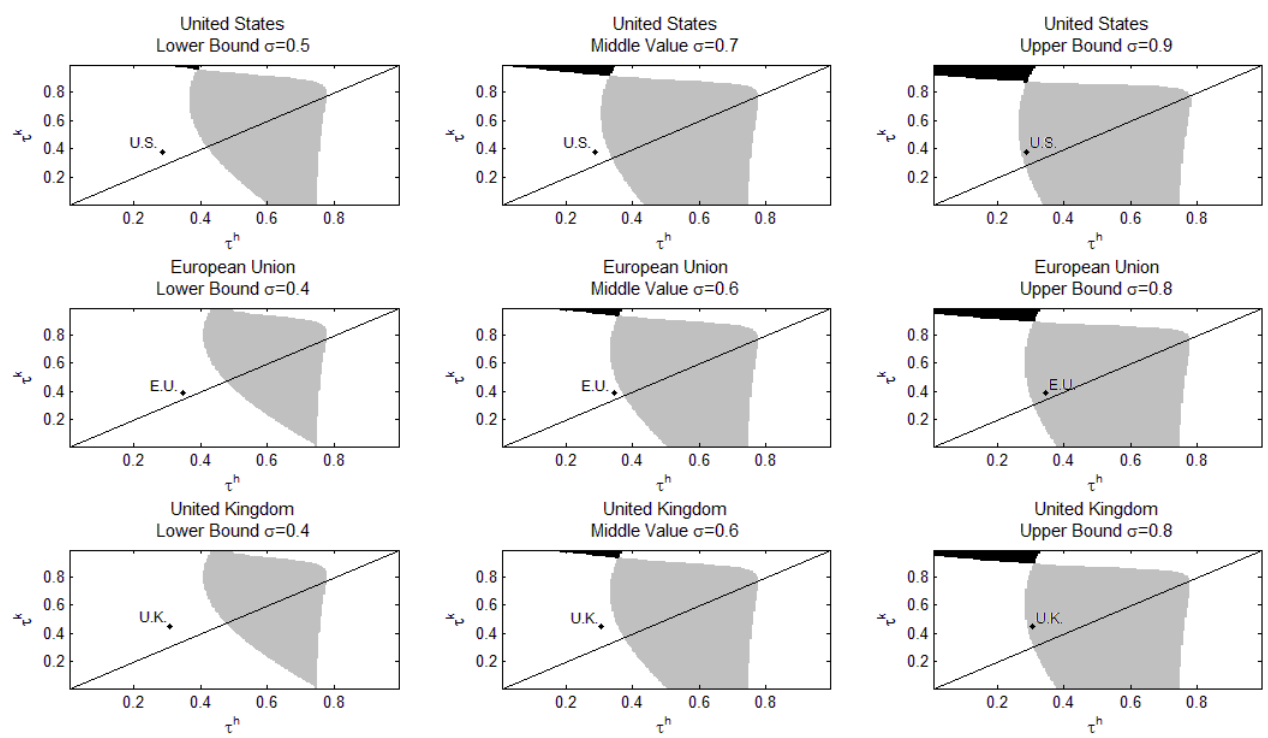

Figure 3 - Endogenous capital and labour income rate for the empirical range of $\sigma$ for the U.S. (first row), the E.U. (second row) and the U.K. (third row).

The graph highlights three findings. First, the model parametrised at the central values of $\sigma$, i.e. 0.7 for the US and 0.6 for EU and UK, delivers determinacy. This is the central result of this exercise and sheds light on the importance of evaluating BBR when factors are gross complements. Second, despite a sensible reduction in the indeterminacy area, the model can still be indeterminate when we consider the high range of estimates of $\sigma$, i.e. 0.9 for the U.S. and 0.8 for both the EU and the UK. Third, the model evaluated in the CD case, i.e. in the Schmitt-Grohé and Uribe (1997) analysis, is indeterminate in the US, the EU and the UK. In other words, given the 2007 tax rates, determinacy requires certain levels of complementarity between production factors, i.e. $\sigma<1$. Furthermore, it is interesting to note the destabilising properties of labour taxation: ceteris paribus, the higher the tax rates on labour the higher the likelihood of indeterminacy. The threshold values of $\sigma$ necessary to obtain determinacy are reported in Table 2 .

Table 2 - Threshold value of $\sigma$ necessary for determinacy in 2007

\begin{tabular}{ll}
\hline \hline US & Determinate if $\sigma \leq 0.82$ \\
EU & Determinate if $\sigma \leq 0.64$ \\
UK & Determinate if $\sigma \leq 0.72$ \\
\hline \hline
\end{tabular}

In the second exercise, we repeat the analysis conducted for 2007 for each year of the period $1995-2007$. Table 3 reports the lowest and highest values of the upper bound of $\sigma$ necessary to obtain determinacy. Changes in the threshold values of $\sigma$ are due to changes in the labour and capital tax rates. A few things are worth stressing. 
First, the upper bound of $\sigma$ necessary to obtain determinacy is always lower than one. This implies that the results of Schmitt-Grohè and Uribe (1997), i.e. a BBR coupled with a CD production function is likely to generate indeterminacy, hold for the period under consideration. Second, the model evaluated at the central values of the estimates of $\sigma$, delivers determinacy in the whole period and for all the countries considered. These two findings allow us to extend the results found for the year 2007 to the period 1995-2007. Lastly, it is interesting to note that there may be the possibility that a BBR delivers determinacy for the entire range of realistic estimates of the elasticity of substitution in the US and UK (last column of Table 3).

\begin{tabular}{ccc} 
Table 3 - Threshold values of $\sigma$ for stability in the period $1995-2007$ \\
\hline \hline US & Doterminate if $\sigma \leq 0.78$ & Highest Value \\
EU & Determinate if $\sigma \leq 0.62$ & Determinate if $\sigma \leq 0.93$ \\
UK & Determinate if $\sigma \leq 0.72$ & Determinate if $\sigma \leq 0.68$ \\
\hline \hline
\end{tabular}

\section{Conclusions}

This paper studies how the introduction of a general class of production function, namely a CES, which is able to match the empirical evidence on the substitutability between labour and capital, changes the local determinacy analysis of a neoclassical economy where fiscal policy follows a balanced-budget rule (BBR).

We obtain two sets of results. Firstly, from a theoretical point of view, we show analytically that the degree of substitutability between production factors is a key ingredient in understanding the (de)stabilising properties of a BBR. In this respect we contribute to the theoretical literature of both the BBR and the CES production function (see among others Guo and Harrison 2004, 2008, Giannaritsarou, 2007, Linnemann, 2008, Guo and Lansing, 2009). Secondly, from a policy point of view, when we calibrate the model consistently with the empirical evidence, i.e. elasticity of substitution below unity, the instability problems that affect the Schmitt-Grohè and Uribe model are sensibly reduced for the US, the EU and the UK. In this respect, our results contribute to the current policy debate and open the door on the plausibility for adopting a BBR. 


\section{References}

Alesina, Alberto \& Perotti, Roberto, 1996. "Fiscal Discipline and the Budget Process," American Economic Review, vol. 86(2), pages 401-07, May.

Antràs, P, 2004, "Is the US aggregate production function Cobb-Douglas? New estimates of the elasticity of substitution", Contributions to Macroeconomics 4: Article 4.

Arrow, Kenneth J. \& Chenery, Hollis S. \& Minhas Bagicha S. \& Solow Robert M., 1961. "Capital-Labor Substitution and Economic Efficiency", Review of Economics and Statistics, Vol. 43, p.225-50.

Azzimonti M. \& Marco B. \& Stephen C., 2010 "Analysing the Case for a Balanced Budget Amendment to the U.S. Constitution" mimeo.

Benhabib Jess \& Farmer Roger E. A., 1994. "Indeterminacy and Increasing Returns," Journal of Economic Theory, Elsevier, vol. 63(1), pages 19-41, June.

Barnes, S., Sebastiá Barriel, M. and Price, S., 2008. "The elasticity of substitution: Evidence from a UK Firm-Level Data Set." Bank Of England Working Paper Series N. 348.

Berndt, E. R, 1976 "Reconciling alternative estimates of the elasticity of substitution", Review of Economics and Statistics 58(1): 59-68.

Besley, Timothy \& Smart, Michael, 2007."Fiscal restraints and voter welfare," Journal of Public Economics, vol. 91(3-4), pages 755-773, April.

Bolt, W. \& P.J.A. van Els, P.J.A., 2000. "Output Gap and Inflation in the EU," DNB Staff Reports 44, Netherlands Central Bank.

Cantore, Cristiano \& León-Ledesma, Miguel A. \& McAdam, Peter \& Willman, Alpo, 2013 " Shocking Stuff: Technology, Hours and Factor Substitution" Journal of the European Economic Association, Forthcoming

Coen, R. M, 1969, "Tax Policy and Investment Behavior: A Comment" American Economic Review, 59:3, pp. 370-379.

Dhrymes, P. J., and P. Zarembka, 1970, "Elasticities of Substitution for Two-Digit Manufacturing Industries: A Correction", Review of Economics and Statistics, February, pp. 115-117.

Diamond, P. A., McFadden, D. and Rodriguez, M. (1978) Measurement of the elasticity of substitution and bias of technical change. In M. Fuss and D. McFadden (eds), Production Economics (Vol. 2, pp. 125-147) Amsterdam: North Holland.

Eggertsson, Gauty, 2008 "Great Expectations and the End of the Depression," American Economic Review, vol. 98(4), pages 1476-1516.

Fuchs, Victor, 1963 "Capital-Labor Substitution: A Note," The Review of Economics and Statistics 45(4):436-438. 
Giannitsarou, Chryssi, 2007."Balanced Budget Rules and Aggregate Instability: The Role of Consumption Taxes," Economic Journal, vol. 117(523), pages 1423-1435, October.

Guo, Jang-Ting \& Harrison, Sharon G., 2004. "Balanced-budget rules and macroeconomic (in)stability," Journal of Economic Theory, Elsevier, vol. 119(2), pages 357-363, December

Guo Jang-Ting \& Harrison Sharon G, 2008. "Useful Government Spending and Macroeconomic (In)stability under Balanced-Budget Rules," Journal of Public Economic Theory, vol. 10(3), pages 383-397, 06.

Guo Jang-Ting \& Lansing Kevin J, 2009, "Capital-Labor Substitution and Equilibrium Indeterminacy", Journal of Economic Dynamics and Control, Vol. 33, Issue 12, 1991-2000.

Hansen, Gary D., 1985. "Indivisible labour and the business cycle," Journal of Monetary Economics, Elsevier, vol. 16(3), pages 309-327, November.

King, Robert G. \& Plosser, Charles I. \& Rebelo, Sergio T., 1988. "Production, growth and business cycles : I. The basic neoclassical model," Journal of Monetary Economics, Elsevier, vol. 21(2-3), pages 195-232.

Klump, R. and de La Grandville, O. (2000). Economic growth and the elasticity of substitution: Two theorems and some suggestions. American Economic Review, 90(1):282-291.

Klump, Rainer \& Marianne Saam 2008, "Calibration of normalised CES production functions in dynamic models", Economics Letters 99(2), pages 256-259

Klump,Rainer, \& McAdam, Peter \& Willman, Alpo, 2007. "The long-term sucCESs of the neoclassical growth model," Oxford Review of Economic Policy, Oxford University Press, vol. 23(1), pages 94114, Spring.

Klump, Rainer. and McAdam, Peter and Willman, Alpo, 2012 "The normalized CES production function - theory and empirics", Journal of Economic Surveys, forthcoming.

León-Ledesma, Miguel \& McAdam, Peter \& Willman Alpo, 2010a. "Identifying the Elasticity of Substitution with Biased Technical Change" American Economic Review, vol. 100.

Leon-Ledesma, M. A., McAdam, P. and Willman, A. 2010b In Dubio pro CES: Supply Estimation with Mis-Specified Technical Change. European Central Bank, Working Paper No. 1175.

León-Ledesma, M. A., Peter McAdam and Alpo Willman, 2011. "Aggregation, the skill premium, and the two-level production function," Working Paper Series 1400, European Central Bank.

Linnemann, Ludger 2008 "Balanced budget rules and macroeconomic stability with non-separable utility", Journal of Macroeconomics 30, 119-215.

Lucas, R. E, 1969 Labor-capital substitution in US manufacturing. In A. C. Harberger and M. J. Bailey (eds ), The Taxation of Income from Capital (pp. 223-274). Washington, D. C.: Brookings Institution. 
Lucas, Robert Jr. \& Stokey, Nancy L., 1983. "Optimal fiscal and monetary policy in an economy without capital," Journal of Monetary Economics, vol. 12(1), pages 55-93.

Maddala, G. S, 1965, Differential Industry Effects and Differential Factor Effects of Technological Change, Memo 36, Research Center in Economic Growth, Stanford University.

McAdam, P. and Willman, A. 2013a "Medium run redux." Macroeconomic Dynamics (forthcoming)

McAdam, P. and Willman, A. 2013b "Technology, Utilization and Inflation: What Drives the New Keynesian Phillips Curve?" Journal of Money Credit and Banking, (forthcoming).

Mendoza, Enrique G. \& Razin, Assaf \& Tesar, Linda L., 1994. "Effective tax rates in macroeconomics: Cross-country estimates of tax rates on factor incomes and consumption," Journal of Monetary Economics, Elsevier, vol. 34(3), pages 297-323, December.

Schmitt-Grohe, Stephanie \& Uribe, Martin, 1997. "Balanced-Budget Rules, Distortionary Taxes, and Aggregate Instability," Journal of Political Economy, University of Chicago Press, vol. 105(5), pages 976-1000, October.

Stockman, David R., 2010, "Balanced-budget rules: Chaos and deterministic sunspots," Journal of Economic Theory, Elsevier, vol. 145(3), pages 1060-1085, May.

Zarembka, Paul, 1970 "On the Empirical Relevance of the CES Production Function," Review of Economics and Statistics. 


\section{Appendix A - The Normalisation Procedure}

As stated before we are using a normalised CES production function. The meaning of the normalisation is that the family of CES production function need a common benchmark point. Since the elasticity of substitution is defined as a point of elasticity we need to fix the benchmark values for the level of production, factor inputs and for the marginal rate of substitution or equivalently for the per-capita production, capital deepening and factor income share.

Therefore we need to recalibrate the parameters $B$ and $\alpha$ each time that the elasticity of substitution $\sigma$ is varied to have the factor shares and the steady state allocations constant. In particular, when $\sigma$ is varied, we want to maintain the value of $B$ equal to its value of the CD output steady-state case and the value of the parameter $\alpha$ is set to maintain at each point the steady state capital income share, therefore its value must be equal to 0.7 .

For our analysis we use as reference point the normalised quantities for the CD case with $\sigma=1$ and $B=1$.

In order to achieve that result the parameters used takes the form:

$$
\begin{gathered}
\alpha=\frac{\bar{\alpha}}{\bar{\alpha}+(1-\bar{\alpha})\left(\frac{K^{C D}}{H^{C D}}\right)^{\psi}} \\
B=\frac{Y^{C D}}{\left[\alpha\left(K^{C D}\right)^{\psi}+(1-\alpha)\left(H^{C D}\right)^{\psi}\right]^{1 / \psi}}
\end{gathered}
$$

where $K^{C D}$ and $H^{C D}$ are the steady state values of capital and labour of a CD production function.

\section{Appendix B - The Log-Linearised System}

In order to study the local determinacy we log-linearise the structural equations around the non-stochastic steady state. Here we present the log-linearise system. A lower case variable identifies $c_{t}=\log \left(\frac{C_{t}}{C}\right) . \hat{\tau}_{t}^{h}$ identifies the log-linearised labour tax rate. $\hat{w}_{t}$ is the log-linearisation real wage and $\hat{\mu}_{t}$ the log-linearised real interest rate.

$$
c_{t}=\frac{-\tau^{h}}{1-\tau^{h}} \widehat{\tau}_{t}^{h}+\hat{w}_{t}
$$




$$
\begin{gathered}
0=\widehat{\tau}_{t}^{h}+\hat{w}_{t}+h_{t} \\
\dot{k}_{t}=\frac{Y}{K} y_{t}-\delta k_{t}+-\frac{C}{K} c_{t} \\
\dot{c}_{t}=\mu \hat{\mu}_{t} \\
\hat{\mu}_{t}=\frac{1}{\sigma}\left(y_{t}-k_{t}\right) \\
\hat{w}_{t}=\frac{1}{\sigma}\left(y_{t}-h_{t}\right) \\
y_{t}=\alpha\left(B \frac{K}{Y}\right)^{\psi} k_{t}+(1-\alpha)\left(B \frac{H}{Y}\right)^{\psi} h_{t}
\end{gathered}
$$

where $\psi=\frac{\sigma-1}{\sigma}$. If we substitute (17) and (18) into the previous expression we obtain:

$$
y_{t}=\bar{\alpha} k_{t}+(1-\bar{\alpha}) h_{t}
$$

\section{Appendix C - The Determinacy Analysis}

The model can be reduced to one involving only two dynamic variables, namely, consumption (non-predetermined) and capital (predetermined), as:

$$
\left[\begin{array}{l}
\dot{c}_{t} \\
\dot{k}_{t}
\end{array}\right]=J\left[\begin{array}{l}
c_{t} \\
k_{t}
\end{array}\right]
$$

where:

$$
J=\left[\begin{array}{cc}
\mu \frac{\bar{\alpha}+\tau^{h}-\bar{\alpha} \tau^{h}-1}{\bar{\alpha}-\sigma \tau^{h}} & -\mu \frac{1}{\sigma}\left(1+\bar{\alpha} \frac{-\sigma \tau^{h}+1}{\sigma \tau^{h}-\bar{\alpha}}\right) \\
\frac{Y}{K} \sigma(1-\bar{\alpha}) \frac{\tau^{h}-1}{\bar{\alpha}-\sigma \tau^{h}}-\frac{C}{K} & \frac{Y}{K} \bar{\alpha} \frac{-\sigma \tau^{h}+1}{\bar{\alpha}-\sigma \tau^{h}}-\delta
\end{array}\right]
$$

The system is determinate if and only if:

$$
\operatorname{Det}(J)<0
$$

While the system displays indeterminacy if and only if:

$$
\operatorname{Det}(J)>0 \cap \operatorname{Trace}(J)<0
$$

i.e. both eigenvalues of $J$ are negative, and it is unstable if and only if:

$$
\operatorname{Det}(J)>0 \cap \operatorname{Trace}(J)>0
$$

i.e. both eigenvalues of $J$ are positive. 


\section{Proof of Propositions 1 and 2}

Determinant and trace of $J$ are respectively:

$$
\begin{gathered}
\operatorname{Det}(J)=\frac{\delta(\rho+\delta)(1-\bar{\alpha})}{\frac{\delta \alpha}{\delta+\rho}\left(\sigma \tau^{h}-\bar{\alpha}\right)}\left((1-\bar{\alpha})\left(\tau^{h}\right)^{2}-2\left(1-\bar{\alpha} \frac{\delta}{\delta+\rho}\right) \tau^{h}+\left(1-\bar{\alpha} \frac{\delta}{\delta+\rho}\right)\right) \\
\operatorname{Trace}(J)=\frac{(\rho+\delta)\left(1-\sigma \tau^{h}\right)-(\rho+\delta)\left(\left(1-\tau^{h}\right)(1-\bar{\alpha})\right)}{\bar{\alpha}-\sigma \tau^{h}}-\delta
\end{gathered}
$$

\section{Sign of the Determinant}

The sign of the determinant is the product of the sign of $\frac{\delta(\rho+\delta)(1-\bar{\alpha})}{\frac{\delta}{\delta+\rho}(\sigma \tau-\bar{\alpha})}$ and $(1-\bar{\alpha})\left(\tau^{h}\right)^{2}-$ $2\left(1-\bar{\alpha} \frac{\delta}{\delta+\rho}\right) \tau^{h}+\left(1-\bar{\alpha} \frac{\delta}{\delta+\rho}\right)$.

Part 1: Sign of $\frac{\delta(\rho+\delta)(1-\bar{\alpha})}{\frac{\delta \alpha}{\delta+\rho}(\sigma \tau-\bar{\alpha})}$ :

$$
\frac{\delta(\rho+\delta)(1-\bar{\alpha})}{\frac{\delta \alpha}{\delta+\rho}(\sigma \tau-\bar{\alpha})}>0 \text { if and only if } \tau^{h}>\frac{\bar{\alpha}}{\sigma}
$$

Part2: Sign of $(1-\bar{\alpha})\left(\tau^{h}\right)^{2}-2\left(1-\bar{\alpha} \frac{\delta}{\delta+\rho}\right) \tau^{h}+\left(1-\bar{\alpha} \frac{\delta}{\delta+\rho}\right)$ :

See Steady State section in the main text, i.e:

$$
(1-\bar{\alpha})\left(\tau^{h}\right)^{2}-2\left(1-\bar{\alpha} \frac{\delta}{\delta+\rho}\right) \tau^{h}+\left(1-\bar{\alpha} \frac{\delta}{\delta+\rho}\right)>0 \text { if and only if } \tau^{h} \in\left[0, \tau^{h *}\right)
$$

Furthermore note that if $\tau^{h}=0.5,(1-\bar{\alpha})\left(\tau^{h}\right)^{2}-2\left(1-\bar{\alpha} \frac{\delta}{\delta+\rho}\right) \tau^{h}+\left(1-\bar{\alpha} \frac{\delta}{\delta+\rho}\right)>0$. Putting Part 1 and part 2 together one obtains that the determinant is positive:

$$
\begin{aligned}
\text { if } \tau^{h *} & >\frac{\bar{\alpha}}{\sigma} \Longrightarrow \tau^{h} \in\left(\frac{\bar{\alpha}}{\sigma}, \tau^{h *}\right) \\
\text { else } \tau^{h *} & <\frac{\bar{\alpha}}{\sigma} \Longrightarrow \tau \in\left(\tau^{h *}, \min \left(\frac{\bar{\alpha}}{\sigma}, 1\right)\right)
\end{aligned}
$$

\section{Sign of the Trace}

The trace of $J$ is:

$$
\operatorname{Trace}(J)=\frac{(\rho+\delta)\left(1-\sigma \tau^{h}\right)-(\rho+\delta)\left(\left(1-\tau^{h}\right)(1-\bar{\alpha})\right)}{\bar{\alpha}-\sigma \tau^{h}}-\delta
$$


It is easy to show that the conditions for $\operatorname{Trace}(J)<0$ are:

$$
\begin{aligned}
\text { if } \bar{\alpha} & <\sigma \leq 1+\frac{\delta(1-\bar{\alpha})}{\rho} \rightarrow \tau^{h}>\frac{\bar{\alpha}}{\sigma} \\
\text { elseif } \sigma & >1+\frac{\delta(1-\bar{\alpha})}{\rho} \rightarrow \frac{\bar{\alpha}}{\sigma}<\tau^{h}<\frac{\bar{\alpha} \rho}{\rho \sigma-(1-\bar{\alpha})(\delta+\rho)}=\varepsilon_{1} \\
\text { elseif } \sigma & <\bar{\alpha} \rightarrow \operatorname{Trace}(J)>0 \forall \tau^{h} \in[0,1]
\end{aligned}
$$

\section{Result 1: Determinacy}

The system as defined in $(26)$ is determinate if and only if $\operatorname{Det}(J)<0$, hence:

$$
\begin{aligned}
\text { if } \sigma & \in[\bar{\alpha},+\infty) \Longrightarrow \tau^{h} \in\left[0, \min \left(\frac{\bar{\alpha}}{\sigma}, \tau^{h *}\right)\right) \cup \tau^{h} \in\left(\max \left(\frac{\bar{\alpha}}{\sigma}, \tau^{h *}\right), 1\right] \\
\text { else } \sigma & \in[0, \bar{\alpha}) \Longrightarrow \tau^{h} \in\left[0, \tau^{h *}\right)
\end{aligned}
$$

\section{Result 2: Indeterminacy-Instability}

Define $\varepsilon=\frac{\bar{\alpha} \rho}{\rho \sigma-(1-\bar{\alpha})(\delta+\rho)}$. The following four cases fully categorise all the model outcomes:

a) If $\sigma \in\left[0,1+\frac{\delta(1-\bar{\alpha})}{\rho}\right]$ and $\frac{\bar{\alpha}}{\sigma}<\tau^{h *}$, the model is indeterminate if $\tau^{h} \in\left(\frac{\bar{\alpha}}{\sigma}, \tau^{h *}\right)$ and determinate if $\tau^{h} \notin\left(\frac{\bar{\alpha}}{\sigma}, \tau^{h *}\right)$.

b) If $\sigma \in\left[0,1+\frac{\delta(1-\bar{\alpha})}{\rho}\right]$ and $\frac{\bar{\alpha}}{\sigma}>\tau^{h *}$, the model is unstable if $\tau^{h} \in\left(\tau^{h *}, \min \left(\frac{\bar{\alpha}}{\sigma}, 1\right)\right)$ and determinate if $\tau^{h} \notin\left(\tau^{h *}, \min \left(\frac{\bar{\alpha}}{\sigma}, 1\right)\right)$.

c) If $\sigma \in\left(1+\frac{\delta(1-\bar{\alpha})}{\rho},+\infty\right)$ and $\varepsilon>\tau^{h *}$, the model is indeterminate if $\tau^{h} \in\left(\frac{\bar{\alpha}}{\sigma}, \tau^{h *}\right)$ and determinate if $\tau^{h} \notin\left(\frac{\bar{\alpha}}{\sigma}, \tau^{h *}\right)$.

d) If $\sigma \in\left(1+\frac{\delta(1-\bar{\alpha})}{\rho},+\infty\right)$ and $\varepsilon<\tau^{h *}$, the model is indeterminate if $\tau^{h} \in\left(\frac{\bar{\alpha}}{\sigma}, \varepsilon\right)$ and unstable if $\tau^{h} \in\left(\varepsilon, \tau^{h *}\right)$ and determinate if $\tau^{h} \notin\left(\frac{\bar{\alpha}}{\sigma}, \tau^{h *}\right)$. 